\title{
2006-2414: A WARMER CLIMATE FOR WOMEN IN ENGINEERING
}

\section{Barb Silver, University of Rhode Island}

Barbara Silver is an Assistant Research Professor of Psychology and Women's Studies at the University of Rhode Island. She received her B.A. in Psychology from Gettysburg College, her M.A. from Connecticut College, and her Ph.D. in Social Psychology from the University of Rhode Island. Her research interests include gender and science, and gender and media. She has served as Program Coordinator for 2 NSF grants focused on women in science, and is currently the NSF ADVANCE grant Program Director.

\section{G. Boudreaux-Bartels, University of Rhode Island}

Prof. G. Faye Boudreaux-Bartels joined the University of Rhode Island Electrical and Computer Engineering Department after earning her PhD from Rice University in 1984. Prior to URI, she worked as a Research Mathematician for Shell Oil Development Company and as a Fulbright Scholar and Instructor of Scientific English at Ecole Nationale Superieure des Télécommunications, Paris. She has published over 100 journal or conference papers on her research in time-frequency representations and digital signal processing, one of which won the "Senior Paper Award" given by the Institute of Electrical and Electronic Engineers (IEEE) Signal Processing Society (SPS). She was elected an IEEE Fellow for her contributions to time-frequency signal representations and their applications. She has served as associate editor of the IEEE Transactions on Signal Processing and of the IEEE Signal Processing Letters, as Vice-Chair of the Digital Signal Processing Technical Committee, as an elected member of the IEEE Signal Processing Society Board of Governors, and as Technical Co-Chair of the Digital Signal Processing Workshop. At URI, she has received several URI Faculty Excellence or Diversity Awards, and the 2001 URI APAW Woman of the Year award. She has served in various URI administrative roles, including Chair of the Faculty Senate, Chair of the Electrical and Computer Engineering Department, and Associate Dean of The Graduate School.

Prof. Boudreaux-Bartels has been very active with outreach activities that encourage young women or under represented ethnic minority students to consider careers in science, math or engineering. She has served as the faculty advisor for the Society of Women Engineers (SWE) for 20 years, and as interim faculty advisor for the URI National Society of Black Engineers and the URI Society of Hispanic Professional Engineers. She co-directed an annual URI summer Bridge program that introduces first year, female engineering students to careers in engineering. She participates in the annual URI SMILE (Science and Math in an Integrated Learning Environment) Engineering Design Challenge Weekend for RI 6th-12th grade minority students and helps organize an annual SWE workshop for 5th-6th grade Girl Scouts to earn a science or engineering badge.

\section{Helen Mederer, University of Rhode Island}

Helen Mederer is Professor of Sociology and Chairperson of the Department of Sociology and Anthropology. Her current research focuses on the intersections of work and family life, particularly as they are affected by gender. She has published studies on the gender dynamics in commercial fishing families and Naval families, and on the allocation of household work within dual worker families. She teaches courses on the sociology of families, aging, gender, and work and family. She is a member of the ADVANCE Leadership Team, the URI President's Commission on the Status of Women, and coordinates the Work/Life Committee at URI.

\section{Lynn Pasquerella, University of Rhode Island}

Lynn Pasquerella is the Interim Vice Provost for Gradaute Studies, Research and Outreach, Professor of Philosophy, and recent Chair of the Institutional Review Board at the University of Rhode Island. In addition, she is a Fellow in the John Hazen White Sr. Center for Ethics and Public Service and was a professor of medical ethics for two years, from 1993-95, in the Brown 
University Medical School's Affinity Group Program.

Dr. Pasquerella is a magna cum laude and Phi Beta Kappa graduate of Mount Holyoke College (A.B., 1980) and Brown University (Ph.D., 1985). She is a recipient of the University of Rhode Island's Teaching Excellence Award and has published extensively in the areas of medical ethics, theoretical and applied ethics, metaphysics, public policy, and the philosophy of law.

In 1998, Professor Pasquerella was honored by Change Magazine and the American Association of Higher Education as one of forty "Young Leaders of the Academy." Her leadership includes service on several departmental, college, and university committees, the New England Association of Schools and Colleges accreditation team, membership on Day Kimball Hospital's Ethics and Institutional Review Board, membership on the advisory board for the Women's Adult Correctional Facility in Rhode Island, and service on the national Committee on Qualifications for Phi Beta Kappa, as well as service as the past President of the Beta Chapter of Phi Beta Kappa of Rhode Island. She has received funding at the national level through the Department of Energy to work on ethical issues related to the Human Genome Project, the National Endowment for the Humanities, the National Science Foundation, the Hewlett Foundation, the American Bar Association, and the Fund For the Improvement of Postsecondary Education.

Professor Pasquerella is a skilled facilitator and has conducted numerous workshops and community conversations on ethics and public administration, critical thinking, instructional development, multiculturalism, and medical and legal ethics.

She and her husband John Kuchle, who is a biologist and photographer, live in Woodstock, Connecticut with their fifteen-year old twins, Pierce and Spencer.

\section{Joan Peckham, University of Rhode Island}

Dr. Peckham is a professor of computer science at the University of Rhode Island. She is a conceptual data modeling researcher who is currently engaged in multidisciplinary research and mentoring in bioinformatics, transportation, women in the sciences, 3-D graphics, undergraduate research, and disaster analysis. She is co-PI on three NSF grants, the ioinformatics core co-leader on an NIH INBRE grant, and a participant in a grant from the New England University Transportation Center. She was the first female tenure track faculty member in her department.

\section{Mercedes River-Hudec, University of Rhode Island}

Dr. Mercedes Rivero Hudec is Associate Dean of Engineering and Associate Professor of Chemical Engineering. Her research interests are in the area of biochemical/environmental engineering. Dr. Rivero was the faculty advisor of SHPE (Society of Hispanic Professional Engineers) for several years and has served as interim advisor of SWE (Society of Women Engineers). She has been an active participant and supporter of SMILE (Science and Math Investigative Learning Experiences) for the past eleven years: SMILE is a program designed for in-state, minority, underrepresented and low-income students in grades 4 to 12. She has also co-directed a summer bridge camp for entering, female, engineering students.

\section{Karen Wishner, University of Rhode Island}

Karen Wishner is a Professor of Oceanography at the University of Rhode Island. She received her B.A. from the University of Chicago and her Ph.D. from Scripps Institution of Oceanography. Her research interests are in marine zooplankton ecology and deep-sea biology. She has led and participated in many oceanographic research programs, including work on submersibles and research ships, and has published many scientific papers. She presently teaches Deep-Sea Biology and Marine Plankton courses. She arrived at URI in 1980 as an Assistant Professor, the first tenure-track woman faculty member in Oceanography hired with a national search. Her recent work as a co-PI with the URI ADVANCE program has been a rewarding effort to improve the work climate and career path for the next generation of women science faculty. 


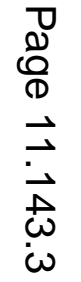




\section{A Warmer Climate for Women in Engineering}

ABSTRACT: In 2000, University of Rhode Island (URI) President Carothers acknowledged, following an extended and sometimes acrimonious AAUP faculty union grievance process, that there had been a climate hostile to women faculty in the College of Engineering. The purpose of this paper is to describe the positive steps that were taken at URI subsequent to that grievance to improve the climate for women faculty in STEM (Science, Technology, Engineering and Math) fields, and to place these steps within a framework for climate change. The paper starts with an overview of the percentages of women nationally in Engineering, followed by a description of the hostile grievance process that took place at URI. Next is a discussion of pro-active measures that were taken by many communities of faculty on the URI campus, including most recently, those of the ADVANCE grant funded by the National Science Foundation. These measures have been guided by a grounded theory approach to climate change that posits simultaneous change in individuals, interactional contexts, and institutional practices. As a result, URI has recruited a significant percentage of new women faculty in STEM fields in a relatively short time, and is working hard to ensure that they are retained.

There have been many recent national initiatives to address the problem of the under representation of women in the science, technology, engineering, and math (STEM) disciplines. It is well recognized that, beyond workplace equity, diversifying the practitioners in Engineering and other STEM fields will enrich these disciplines by bringing different perspectives, skills, and values to the fore, will help America remain globally competitive, and will more responsibly integrate Engineering practice with societal needs. Importantly, women and minority faculty also provide critically needed role models needed to attract and retain a more diverse student population. In Engineering, women comprise only about $20 \%$ of bachelor degree recipients, and are only $6 \%$ of full professors, $12 \%$ of associate professors, and $18 \%$ of assistant professors. ${ }^{[1]}$ In addition to recruitment barriers, retention and advancement provide additional obstacles. Reduced tenure rates, slower promotion rates, inflexible and demanding work schedules that make balancing work and family difficult, heavy service and teaching loads, and a maledominated, often hostile work climate that does not validate the needs or contributions of women participants all contribute to a higher attrition rate ${ }^{[2]-[5]}$ for women than for men STEM faculty. The University of Rhode Island was representative of these trends until a series of events, culminating in the activities of the NSF ADVANCE program, provided avenues for positive change in the College of Engineering, which now serves as a model for diversity at the University.

\section{Hostile Conditions for Women at URI}

Until the mid 1990's, there was never more than 1-2 female faculty in the College of Engineering at the University of Rhode Island. In 1997, the number of women faculty had increased to three out of 68 faculty members, which at $4.4 \%$, was typical of US national averages. However, in quick succession the URI Engineering College lost two new assistant professors in one department, and the College of Engineering was becoming known as a hostile 
place for women. There were many stories about the chilly climate and a number of women faculty members and graduate students had left over a very short period of time. The purpose of this paper is to give a quick overview of how the grievance process, settlement and subsequent actions at URI, with the help of a recent NSF Advance grant have helped the College of Engineering at URI evolve over the past decade from one having one of the most inhospitable climates for women on campus to one that is a model for diversity and positive change at this university.

In the spring of 1996, of the 68 faculty members in the College of Engineering, three were women and only one had tenure. In addition, two other women faculty had been hired previously, but had left before getting tenure. In 1998, the most recently hired female faculty member left the university unhappy with the way she had been treated. She felt the level of hostility towards her in her department was so great that she asked for a faculty witness from outside the College to attend her exit interview with the Dean of Engineering. In September 1998, the American Association of University Professor (AAUP) filed a grievance on behalf of the remaining women faculty members in the College of Engineering against the College's Dean of many years. The grievance process was protracted and arduous. During the eighteen months process, the chilly climate within the College of Engineering increased. "Silence was the modus operandi. With very few exceptions, no other Engineering faculty members questioned what was going on and why a grievance was filed. False rumors denigrating to us were rampant," said one of the female complainants.

Outside the College of Engineering there was more concern and awareness of the seriousness of the situation and more people were willing to support the women involved in the grievance. In particular, an informal group of women scientists who had been meeting monthly for lunch for almost 20 years decided to voice their support for the women Engineering faculty. They invited faculty from the Women's Studies program, who had taken an activist role for women's rights in years past, to join with them to form a Women's Equity Committee. Over several meetings, the group drafted a written petition to URI President and Provost that described the chilly campus climate and presented a list of changes that needed to be addressed. Over 130 people at URI signed the petition. Among the issues the Women's Equity Committee discussed with the President and the Provost were consciousness raising about the hostile climate at URI, particularly in some programs; helping to ensure a resolution to the mediation process in Engineering; attention to the incidence of pornographic screens in Engineering labs; the development of a Commission on the Status of Women; the promise of a new Women's Center; a reviving the sexual harassment committee; discussions with the Affirmative Action office regarding equity for women; involvement in major campus searches (e.g., Affirmative Action Officer); testing for possible cancerous agents at URI and an epidemiological study of a possible cancer cluster; more equitable salary and workload for some individuals; a subcommittee to investigate salary, workload and facilities across campus; etc.

In March 2000, President Robert L. Carothers acknowledged that there was a climate hostile to women in the College of Engineering and agreed to a number of corrective actions. In a statement, President Carothers said that,

"[The] Dean of the College of Engineering bears prime responsibility for the climate in the College. He has not challenged those whose actions contributed to this climate ... He has not assured that women on the faculty are treated equitably and fairly. We believe 
that women faculty have been adversely affected professionally by the hostile climate toward women [in Engineering]. Some believed it necessary to resign their positions and pursue their professional lives elsewhere" (McVicar, 25 March 2000, Providence Journal).

As a result of the grievance settlement to the sexual harassment in the College of Engineering, an independent audit team visited the University of Rhode Island during Fall 2000 to examine the climate in the College of Engineering, identify tangible and intangible factors that retard the achievement of full professional equality and recommend effective remedial measures. ${ }^{\mathrm{a}}$ The final report was released in December 2000. ${ }^{\mathrm{b}}$ The report lists a number of factors that:

"contributed to a belief that some male professors and administrators did not view female colleagues as equals but rather as second-class members of the faculty. Adding to the women's discomfort was their perception that individuals who raised complaints about disparate treatment were viewed as 'troublemakers,' a perception that discouraged the seeking of redress for mistreatment."

Among the factors cited by the independent audit team were:

- Demeaning and insulting statements and remarks made by the Dean and faculty members toward women faculty

- "Window dressing" efforts by the Dean to support women in Engineering programs rather than providing adequate funding for such efforts

- Public treatment of women faculty in a less respectful manner than male faculty, such as addressing the women by the first names and the men by their title and last names

- Commenting to women faculty on the perceived appropriateness of their clothing

- The failure to carry out annual performance reviews in the manner specified in the collective bargaining agreement

\section{Legal Considerations Related to the Hostile Climate Grievance}

Three engineers at the University of Rhode Island filed grievances alleging sexual discrimination in violation of Title VII of the Civil Rights Act of 1964. It's instructive to note that there was much misinformation among the faculty and some administrators regarding whether sexual harassment can occur if there had been no requests for sexual favors. According to Title VII, section 703 ,

"It shall be unlawful employment practice for an employer_-(1) to fail or refuse to hire or to discharge any individual, or otherwise to discriminate against any individual with respect to his [sic] compensation, terms, conditions, or privileges of employment, because of such individual's race, color, religion, sex, or national origin; or (2) to limit, segregate, or classify his employees or applicants for employment in any way which would deprive or tend to deprive any individual of employment opportunities or otherwise adversely affect his status as an employee because of such individual's race, color, religion, sex, or national origin." 
At issue was whether female engineers at the University of Rhode Island were victims of disparate treatment with respect to work assignments, start-up funds, office and lab space, and annual review processes for promotion and tenure. In addition, there were charges of sexual harassment. The University was accused of failing to enforce policies that prohibited the downloading of pornography using University computers in an Engineering lab, in particular, during one of the female professor's classes. Since the activity occurred even after complaints had been issued by female faculty and students, sexual harassment allegations were made based on the creation of a hostile work environment. While merely offensive conduct is not prohibited, an employer has broken the law if " a reasonable person would find the workplace so filled with sexual improprieties that it had been a hostile and abusive environment" (Harris v. Forklift, 1993).

In spite of widespread disagreement in the courts about exactly which behavior constitutes sexual harassment, in 1980 the Equal Employment Opportunity Commission (EEOC) developed guidelines for determining whether someone was a victim of sexual harassment. According to these guidelines, unwelcome sexual advances, requests for sexual favors, and other verbal or physical conduct of a sexual nature constitute sexual harassment when:

(1) Submission to such conduct is made either explicitly or implicitly a term or condition of an individual's employment.

(2.) Submission or rejection of such conduct by an individual is used as the basis for employment decisions affecting such individual.

Or,

(3.) Such conduct has the purpose or effect of unreasonably interfering with an individual's work performance or creating an intimidating, hostile, or offensive work environment.

Under the EEOC guidelines, sexual harassment is considered a form of sexual discrimination. Contained within the general description of sexual harassment are two specific types-coercive, or quid pro quo sexual harassment and non-coercive or hostile environment sexual harassment. Coercive sexual harassment includes unwelcome sexual advances, a negative response to the advances, the presence of intimidation when the one making the advances holds more power, and the suggestion that inappropriate benefits or penalties will accrue. There were no claims of this form of sex discrimination at the University of Rhode Island. With respect to hostile environment sexual harassment, it should be noted that intent is not necessary. The offending behavior may have the effect of creating a hostile environment without the intent to do so. The University is nevertheless responsible for eliminating and preventing such conduct.

The case at the University of Rhode Island was settled out of court, but subsequent discussions in the Engineering Diversity Task Force raised questions that have been brought forward in other, non-URI, legal cases. One of the most interesting is whether "the reasonable woman standard" as opposed to "the reasonable person standard" should be 
used to determine whether behavior is sufficiently offensive to create a hostile environment. Courts have gone both ways in assessing harassment claims.

\section{Positive Change in the College of Engineering}

The Independent Audit Team recommended changes in 1) recruitment and hiring, 2) retention of faculty, and 3) communications and education strategy. Most significantly, the audit team recommended that URI select a new Dean who is supportive of gender equity and skilled in dealing with gender and diversity issues. In addition, the report recommends:

The recruitment of a "critical mass" of female faculty, including at the senior level, through the addition of new lines

Develop steps to insure the retention of female faculty, including providing adequate start-up funds, competitive salaries, helpful mentoring, fair evaluation and supportive departmental leadership

Improve communications about gender equity issues so that faculty can deal openly and fairly with issues raised by the presence of female faculty members.

The College of Engineering Diversity Committee was activated and charged with responding to the requirements of the grievance settlement and the Independent Audit's recommendations. Female faculty and faculty of color from outside the College were added to the committee to increase the perspective of under represented faculty. The Engineering Diversity committee drafted policy language and proposed it to the Engineering faculty to be adopted as part of the College's mission statement and to be prominently mentioned on the College's web site.

Attention was paid to how much service work under represented faculty were being requested to perform. The Engineering Diversity Committee drafted a conflict resolution procedure, which included a flow chart describing the steps that faculty members could take to address dispute issues of conflict within the Engineering departments, as well as a Best Practices in Recruiting and Retention. The Engineering Dean gave the committee a budget for dispersing funds to improve the environment in the College for underrepresented groups, and for other initiatives such as trips to conferences for the local chapter of the NSBE (National Society of Black Engineers) and diversity seminars by outside researchers. The Diversity Committee supported a summer "Bridge" program for first-year female Engineering students. They supported the recommendation of a new position of Associate Dean of Diversity to be created. Over the next few years, 2-3 new female Engineering faculty and a new Engineering Dean were hired.

\section{ADVANCE \& Its Initiatives}

Since the grievance settlement, one of the most powerful forces for climate change at URI has been the result of a 5 year, \$3.5 million ADVANCE Institutional Transformation grant from the National Science Foundation awarded in September 2003. The primary goal of the URI ADVANCE program is to increase the representation of women in the science, technology, Engineering, and mathematics (STEM) disciplines, to promote their careers, and to improve the institutional climate for women scientists and engineers. Through a 5-year, multi-level approach, URI will: 1) substantially increase the number of ranked women faculty in the STEM departments, 2) provide existing women STEM faculty with career development and training opportunities, 3) improve social support services for women faculty, 4) systematically educate 
and promote awareness of women-in-science issues at the individual, departmental, and administrative levels, and 5) develop and utilize a broadly applicable collaborative organizational change model.

\section{Recruitment}

When ADVANCE began, there were 36 full-time ranked women faculty in the STEM fields, representing $14.2 \%$ of STEM faculty. In Engineering there were 5 full-time ranked women faculty, or about 7\%. ADVANCE's 5-year goal was to increase the STEM number by 10, and by 15 over the subsequent 5 -year period, for a total increase in representation after 10 years from $14 \%$ to $20 \%$. The program approach is to provide 1) education about best practices in recruiting for diversity, and 2) recruitment funding opportunities to STEM departments engaged in the hiring process.

Recruitment, in the form of a Faculty Fellows program, has been a successful centerpiece of the ADVANCE. This program allowed the University to bring in new women faculty in STEM fields. Money was budgeted in the NSF ADVANCE grant to "pre-book", or bring in, new women faculty from 1-3 years before the actual faculty openings were scheduled to occur due to retirement or increased funding for faculty positions from the state of Rhode Island. URI is the state's flagship university; however, the state provides less than $20 \%$ of its financial resources. These new faculty were hired into a new position, called NSF ADVANCE Fellows or NSF ADVANCE Research Assistant Professors. The expectation is that the Faculty Fellows would spend their initial few years at URI focusing primarily on research activities while their salaries were being paid for by the NSF ADVANCE grant. ADVANCE Faculty Fellows were assigned significantly reduced teaching and service loads, and given assurances that as long as they were reasonably productive, they would transition automatically to a tenure-track faculty position as soon as one became available in the next 1-3 years.

Congruent with this program is an infrastructure of enhanced support and training, which has been offered to other women STEM faculty. This includes a yearlong series of career workshops, a mentor training program, a topical lunch series, a social networking program, and visiting speakers. The ADVANCE Incentive Fund, eventually fully supported by URI, provides awards to research endeavors that include women faculty collaborators, especially Pre-Faculty Fellows and junior faculty, and departmental or individual efforts that promote relevant climate or policy changes. In addition, proactive efforts have been made to educate the URI community about the issues surrounding the balancing of work and family, and have included a new parental leave policy for faculty that includes paid leave for both mothers and fathers.

As shown in Figure 1, URI is making significant strides in this area. In academic years (AY) 2001-2003, prior to ADVANCE, 35\% of new STEM hires were women. Since then, 14, or 50\%, of all new tenure-line hires in the STEM disciplines have been women. In the College of Engineering, five women, constituting most of the new tenure lines, bring the number of fulltime female Engineering faculty to 8, or approximately 12\%. ADVANCE has been directly or indirectly involved in 10 of the STEM hires, having reached the 5-year goal in just 2 years. Two of these hires were in the College of Engineering (one in Computer Engineering and one in Civil 
Engineering). ADVANCE support and training has been provided to five of the six new Engineering hires.

\section{Comparison of Hired Faculty Since ADVANCE}

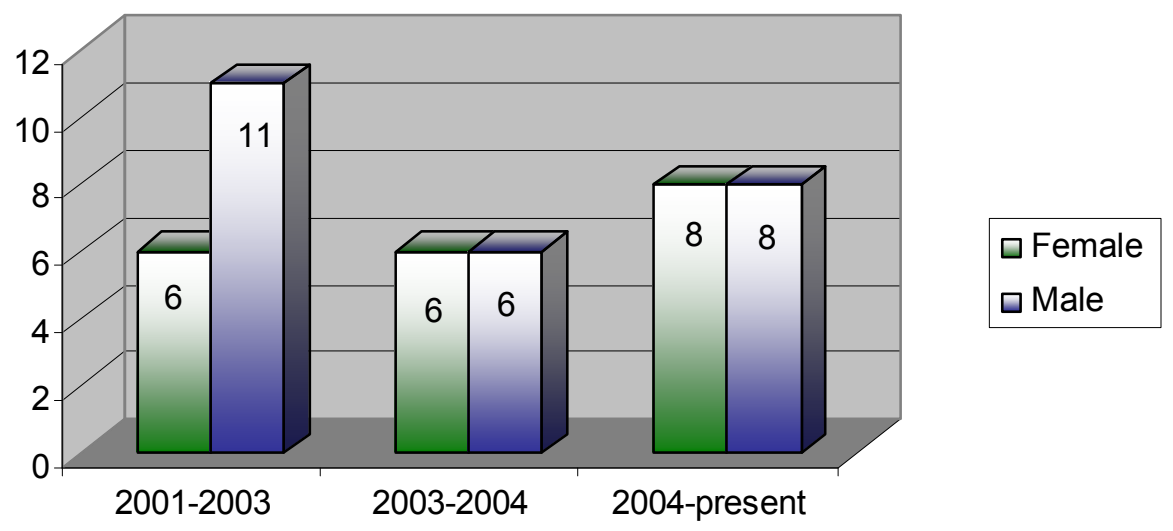

Figure 1: Comparison of hired faculty at URI since ADVANCE.

To hire these female Faculty Fellows, special attention was paid to the recruitment process including:

1. Special wording in the ads strongly stated that the successful candidates must significantly contribute to the goal of increasing the representation of females in tenure track and tenured positions at URI.

2. Applicants were told that although these were to be ADVANCE faculty Fellow positions, there would be seamless transition into regular tenure track positions in 1-3 years and that there would be reduced teaching responsibilities before this transition. That is, special care was taken to assure ADVANCE fellows that this was not a post-doctoral position with additional steps needed to move into a full-fledged tenure track position. Instead, movement into these tenure track lines would be straightforward.

3. At least one ADVANCE leadership team member was a part of each search committee. Otherwise, the committees were configured by a mix of departmental and other faculty appropriate to the discipline, instructed to carry out their mission as usual at URI. The major difference was that search committees and their departments received ADVANCE training and/or consultation including attention to the special issues of female applicants.

4. Those Faculty Fellow Candidates brought to campus for an interview were introduced to the ADVANCE staff and faculty and informed of the assistance that would be provided to successful candidates through the Faculty Fellows and mentoring programs. The URI climate changes, including the faculty parental leave policy were discussed in detail. ADVANCE team members and other female STEM faculty also took each candidate to lunch to create an environment in which sensitive questions and issues, e.g. parental leave policy, could be addressed.

5. Special steps were taken to assist any candidates with dual career needs. For example, the Engineering Dean used faculty connections to help one candidate's husband to find a 
job with local industry. The GSO Dean hired two significant others into research faculty positions.

6. Financial incentives were provided to departments that successfully made ADVANCE hires. This included faculty salary for 1-3 years for 6 faculty fellows, and a modest percentage of the startup cost for 1 other. Provost M. Beverly Swan was a strong partner in her willingness to grant tenure track lines to departments in which women were most severely underrepresented and that were willing to engage in an ADVANCE searches.

It is significant to note that the first two searches and hires under this program occurred in Engineering, providing a model for the other colleges for how to conduct an effective search in this unique context. Of surprise to the search committees was the high number of excellent applicants, and the exceptionally high quality of the eventual hires. This was important information to many on campus who assumed that there are few women in Engineering simply because there are no highly qualified female candidates available, or that all those who were available would be hired by other more competitive institutions. Although only one hire had been approved for the College of Engineering, the high quality of the pools resulted in high interest among the faculty and Provost to hire more than just one faculty member from each search. Upon request, the Provost Swan approved additional hires from ADVANCE applicant pools with additional university funds. The recruitment piece has been a very successful part of this program, resulting not only in female hires, but increased awareness about how effective searches can yield surprising results.

\section{Faculty Development Activities}

After faculty are recruited to URI, their experiences during the first few years play a large role in determining whether they stay at the university and enjoy a successful career and fulfilling personal life. The ADVANCE program has undertaken a number of activities designed to enhance the retention of women STEM faculty by providing training, small grants, and social networking opportunities. ADVANCE programs include workshops, senior faculty mentor training, small research awards, and monthly topical lunches. All events are heavily advertised, contributing to high attendance numbers.

Workshops. Faculty succeed best when they have the skills and knowledge necessary for career advancement. ADVANCE has sponsored several workshops for faculty, each running for 2 - 3 hours. Most of the workshop facilitators and panelists have been in-house; thus, these activities have been done at low cost and should be easy to continue beyond the duration of grant funding. Including lunch has been a good way to enhance attendance.

The Negotiations Workshop was facilitated by faculty members who have experience in negotiations training, including two from the College of Engineering and one from the College of Business Administration. The workshop focused on negotiations for women and followed a panel format, with role-plays and discussion.

Two Mentoring Workshops were held, with participation by women and men STEM faculty. The first one, near the beginning of the ADVANCE program, focused on providing suggestions for senior faculty serving as mentors. It was facilitated by the head of the Instructional 
Development Program and included a panel of six: three experienced mentors and three new faculty mentees. Engineers were represented as panelists in both categories. Following the panel presentation, the audience participated in small group discussions about specific mentoring scenarios and generated a best practices list for mentors. The second Mentoring Workshop a year later was equally divided between the experiences of the mentees (especially the new ADVANCE Fellows who had now been at URI for several months to a year) and senior faculty mentors. Mentees met for several hours in the morning and mentors met for a similar period in the afternoon, with joint discussion over lunch. This workshop was facilitated by members of the ADVANCE team (led by a Chair from Engineering) and included a presentation by a Sociology professor describing mentoring relationships. Participants discussed their experiences and expectations, which were compared to research findings on mentoring, and generated many suggestions.

Several grant-related workshops have also been held. ADVANCE collaborated with the URI Research Office in sponsoring a series of Grant Development Workshops geared toward junior faculty; these included sessions on Securing Funding, Collaborative Proposals, and Grant Funding. A Post-Award Grant Management Workshop is planned in the near future to provide concrete advice for navigating the university bureaucracy once a grant is received.

Monthly Writing Workshops, facilitated by a member of the ADVANCE leadership team, are also being held. These provide a defined time set aside for scientific writing for grants or publications. The first session featured a professional writing coach who provided many specific suggestions for initiating and completing manuscripts, and subsequent sessions have included short presentations by successful URI STEM faculty writers. Participants work individually or collaboratively on their own projects.

Mentoring Activities. The promotion of a policy of pro-active mentoring for new faculty has been an important contribution of ADVANCE to the academic community, including Engineering. ADVANCE members and senior university administrators have emphasized the importance of mentoring to new and senior faculty and departmental administrators. In addition to the mentoring workshops, ADVANCE has compiled a Faculty Mentoring Handbook of best practices and summary flyers for mentors and mentees. The recommended policy now is for every new STEM faculty member to be assigned at least two mentors, one from within the department and one from outside. ADVANCE has worked with chairs and deans to make sure that the mentors are appropriate, for example, resolving some situations where mentors were actually competing for departmental resources with their mentees. The mentoring workshops have promoted the concepts that mentoring is an essential and positive component of career success (not a remedial need) and that multiple mentors are best for addressing the many concerns of a faculty member. Efforts are now underway to incorporate language in the faculty promotion criteria that explicitly acknowledges a contribution to mentoring other faculty. This increased awareness and positive attitude about the benefits of mentoring is helping the College of Engineering to be more pro-active in retention efforts with its new women faculty. These best practices are also spreading out to the other non-STEM departments at the university.

Incentive Fund. The ADVANCE Incentive Award Program is \$40,000-a-year fund, established jointly by ADVANCE and the Provost's office, to help promote the careers of women STEM 
faculty and efforts by individuals (female or male) that promote climate or organizational change conducive to the successful recruitment or retention of women in STEM fields. As of 2005, 15 awards have been made, including 3 to Engineering faculty. Funding has been used as seed money for research, summer salary for proposal preparation, small items of equipment, collaboration with a senior faculty member, travel to conferences, and a speaker series in which the speakers gave both scientific seminars and also discussed issues pertinent to women faculty and students in the department. Assistant professors are given some priority, but women (and some men) at all levels and in many departments have received funding.

Topical Lunches. A monthly series of casual topical lunches for women STEM faculty has proven to be a successful way of networking within the university community and exchanging advice about teaching, research, and balancing one's career and personal life. Typically, selected panelists from the faculty describe some of their personal experiences as a means of generating good discussions. Topics have included Thinking about Tenure from the Start, Strategies for Being Heard, Gender-Sensitive Teaching, Selecting Good Students, Publishing a Paper, preview of key concepts from the work of upcoming visiting speakers (Virginia Valian, Robert Drago), Work-Work and Home-Work, URI's new family leave policy, dual career issues, and Women of Wisdom (perspectives from senior and retired faculty). Lunch is free to participants. For women in departments with few other female faculty or mostly older faculty, this is a relaxed and important way to keep in touch with others dealing with similar professional and personal issues.

There is also a separate Chairs' Discussion Forum, organized by the Provost in partnership with ADVANCE, the John Hazen White Sr. Center for Ethics and Public Service, and an internal leadership training group. These are topical lunch discussions facilitated by former chairs and designed to support chairs and promote excellence in leadership.

\section{Work-Life-Family Support}

It is being increasingly recognized that an effective workplace is one in which a flexible work environment is provided where the responsibilities of work, family and personal needs can be balanced. This is particularly true for women faculty who still assume the majority of family caregiving responsibilities, often while negotiating the promotion and tenure process. The ADVANCE program has provided education and increased awareness regarding these issues. In addition to providing networks of support to women faculty through social offerings, topical lunches, and other venues, ADVANCE has sponsored speakers and workshops on these topics. A key accomplishment includes the co-authoring (with the President's Commission on the Status of Women) and passage of a new Parental Leave Policy for Faculty, which includes 6 weeks of paid leave for both new mothers and fathers. As of its adoption one year ago, 11 faculty members have taken advantage of the policy, several of whom have been men. In the College of Engineering, three women have recently given birth, two of whom used the new leave policy. Both of the Engineering women were readily granted leave, with no negative experiences reported either during the leave negotiation, or upon their return, experiences that would have been highly unlikely a few short years ago. 


\section{Climate Change}

In addition to recruitment, the ADVANCE program aims to educate departments about chilly climate issues and factors that aid retention of women and other under-represented faculty. To that end, departments who were given permission to conduct a search for a faculty fellow were asked to participate in associated ADVANCE activities. This included having an ADVANCE representative on each search committee to advise about best search practices. In addition, each department who received a Faculty Fellow position was asked to participate in a department climate workshop. It was recognized that convincing a department to spend half a day in a workshop understanding what factors contribute to an excellent working environment might be a hard sell for many faculty in the STEM disciplines. Departments were assured that the workshop would benefit the entire department so that all faculty would thrive. From an economic standpoint, chairs were also reminded that the attrition of faculty is enormously expensive, and that an unwelcoming work environment has been documented as a significant factor in the attrition of female STEM faculty. Also, with very tight operating budgets and a near hiring freeze at the time, the tradeoff of receiving salary and partial start-up money for a sorely needed new faculty member was an attractive bargain. The Civil and Computer Engineering Departments agreed and were among the first at URI to participate.

While initially reluctant in some cases, the outcomes of the workshops were very positive, and resulted in action plans that were inclusive of the needs of all faculty members, including women. Banking on the initial positive feedback received from the departments seeking ADVANCE fellows, other Engineering departments were approached. To date, 4 of the 6 Engineering departments have participated in initial and follow-up workshops, and the remaining 2 have expressed willingness to schedule a workshop when time allows.

Climate change is also promoted through the sponsorship of public forums and presentations aimed at increasing awareness of these issues facing underrepresented groups, particularly women. Outside speakers, entertainment venues, and research presentations by the faculty fellows, all preceded by vigorous publicity, have contributed to raising awareness.

\section{Assessment and Evaluation}

In initial presentations to URI about the ADVANCE program, ADVANCE documented the status of women STEM faculty both nationally and at the University, presenting data that were troubling, both from an equity perspective and an economic perspective. Basically, these data indicated that women represent $14.3 \%$ of the STEM faculty at URI (well below the national average of $22 \%$ ), and only $7 \%$ of faculty in Engineering. These data provided initial benchmarks that will be updated annually. In addition to tracking numbers of women, other indicators include salary and start-up comparisons, promotion and tenure rates, attrition comparisons, leadership appointments, etc. These data will also be aggregated with similar data collected at the other 18 ADVANCE institutions to evaluate the impact the program will have at a national level. We hope to use these data in future presentations to departments and administrators to increase campus awareness about the status of women at URI and how URI compares to other universities. 
In the first year of the grant, a campus-wide climate survey was conducted, assessing faculty experiences and perceptions of the working climate at URI. Approximately 39\% of all URI faculty, including 34\% of all Engineering faculty, responded. Results will be used to help departments think about where they excel and about ways to increase the job satisfaction of their faculty. In Year 4, the survey will be reissued, providing comparative measures for gauging change over the grant period. A sample of preliminary findings that will be more fully discussed in future publications include:

- STEM faculty report more career satisfaction than non-STEM faculty

- Although men report fewer perceptions of gender inequity than women, there are no significant differences in perceptions of inequity between STEM and non-STEM faculty

- Men STEM faculty perceive more positive interactions with their colleagues than do women STEM faculty

Other aspects of our program are being individually evaluated:

Recruitment: In addition to tracking numbers, the accomplishments faculty fellows have been impressive. Their transition into tenure-line positions will provide the ultimate evaluation data about the success of the faculty fellows program.

Faculty Development: Evaluations of faculty workshops, the mentoring program and topical lunches, via very short questionnaires, have been very positive. Attendance at all events has been very good, lending further validation that these efforts are well received. Incentive award recipients are required to submit a final report identifying the outcomes of their projects.

Work-Life: Use of the new Parental Leave Policy is being tracked, and interviews are faculty being conducted concerning parental leave, dual career issues, and general experiences of new faculty members. The 2007 climate survey will further assess faculty perceptions of work-life balance options at the university.

Climate: Departments that have participated in climate workshops will also engage in follow-up self-evaluations to determine how well their action plans have been implemented or how to modify them. The 2007 climate survey will contribute to our understanding of the impact of the department workshops, by measuring changes in perceptions of department climate from 2004 against departments who did not participate in a workshop.

Sustainability. The ultimate measure of program effectiveness will be the number of initiatives that remain in place after the grant period is over. ADVANCE is working hard to ensure that our efforts result in permanent institutional change. An Internal Advisory Council, consisting of top university administrators, will provide the leadership to ensure sustainable change is realized.

\section{Summary: A Synthesis of Efforts}

Several factors have worked together to create an improved climate for women and a shift in perspective in the COE at URI. These factors can be understood within a framework that includes 3 levels of analysis, and that were implemented in a relevant time sequence.

Institutional: As a result of the courage and tenacity of the women in Engineering, the Women's Equity Committee, and the leadership at URI, institutional changes were mandated for the College. These efforts represent structural, top-down approaches that provided necessary first steps, and included: 
1. Establishing leadership positions: Dean and Associate Dean

2. Establishing policies: mission statement, recruitment and retention goals, best practices documents

3. Establishing formal oversight committee: Diversity Committee

4. Providing financial incentives to promote diversity efforts (Diversity Committee fund)

Following initiation of the ADVANCE program in 2003, further institutional changes occurred:

5. Offering a formal recruitment program with financial incentives to encourage hiring of women faculty (ADVANCE Faculty Fellows Program)

6. Offering a formal Incentive program to promote research by women (ADVANCE Incentive Fund)

7. Providing an officially endorsed parental leave policy

8. Establishing formal university committee: Work/Life Committee

Individual: There have been several means by which individuals have been asked to think about diversity issues in Engineering. Faculty from each Engineering department were asked to participate on the Diversity Committee. The Committee was charged with ensuring that the terms of the grievance settlement were met and with dispersing funds to individuals who proposed initiatives that promoted diversity in the COE. By eliciting faculty participation on the committee, diversity was being actively championed in the COE by individual members of the College, representing a bottom-up, peer-based, grassroots promotion of the institutional goals required as a result of the grievance. In addition, the efforts of ADVANCE were made known to most, if not all, Engineering faculty. Many faculty members, including all chairs, have been exposed to ADVANCE presentations, requests to serve on committees, lunch invitations, mailings, Faculty Fellow receptions, personal invitations to attend workshops, etc. Finally, measures of individual attitudes and behaviors towards gender equity were assessed by ADVANCE's faculty climate survey, and these measures are being analyzed on a department level to identify departmental intention and readiness to embrace further changes.

There is much indication that on an individual level, most faculty support the goals of gender equity and faculty diversity. First, it is interesting to note that the results of the campus-wide climate survey initiated after the first year of the grant period indicated that fully $80 \%$ of respondents indicated they were willing or already engaged in key behaviors that support the careers of women in STEM. Second, the department climate workshop evaluations nearly unanimously applauded the opportunity to communicate with peers and to understand other faculty member's experiences and concerns. Finally, attendance at other ADVANCE sponsored events, such as the recent Mentor Training Program or the Faculty Fellows Lunch Panel Presentations during URI Research Week, has been excellent.

Interactional. Insights from social science theory ${ }^{[6],[7]}$ provide awareness that institutional and individual efforts to promote positive change may be minimally effective unless change at the interactional level is encouraged. It is interesting to note that, although climate survey results indicate $80 \%$ of all faculty report supporting the careers of women faculty, during the same time period women STEM faculty reported in focus groups feelings of exclusion and isolation. Institutional change in formal policies and interventions in individual intentions to engage in behaviors that promote the careers of women in Engineering are necessary but not sufficient in 
bringing about transformative and enduring climate change. In other words, particular attention is focused on how to translate individual motivation and intentions to engage in equitable behaviors into interactional practices that no longer endorse traditional gender assumptions and accountability to others' expectations in interactions. Examples include: uneven allocation of information and resources, workload, cognitive bias about abilities, or work assignment preferences. This iterative process needs to occur within an institutional climate of fair and inclusive policies and procedures. Transformative change, therefore, needs to occur on three levels: individual, interactional, and institutional. ${ }^{[6]-[9]}$

The initial positive outcomes of the grievance set the stage for real change in the COE. While they were necessary first steps, they represented institutional and individual efforts that needed reinforcement, validation, and the key missing interactional component. The ADVANCE program was launched at a propitious time point for the COE, and provided those key additional features that cemented initial progress and that will hopefully guarantee lasting change.

1. Much publicity about and interaction with exceptional women Engineering candidates and eventual new faculty members that worked to dispel traditional myths.

2. Provision of social networking opportunities that helped to bridge communication divides among women and men faculty and reduce the isolation commonly experienced by women in a primarily male arena.

3. Participation in department climate workshops that provided badly needed (and much appreciated) communication opportunities for department members, and an increased understanding of the invisible yet toxic nature of a chilly working climate.

4. Increased understanding about cultural factors, psychosocial processes, and the unconscious but powerful assumptions that act invisibly to undermine women's success.

5. Peer group endorsement, as the efforts of ADVANCE have involved faculty in all STEM departments.

The overall impact of the ADVANCE program was to validate, from a national and data driven perspective, what the COE was experiencing locally, and make highly and repeatedly visible the issues that surround the recruitment and retention of women STEM faculty. Through processes that enabled interactional-level change, ADVANCE has helped normalize the subject of gender equity and initiatives toward diversity. Departments, colleges, or institutions that strive for a warmer climate for women faculty in Engineering should consider the important interplay between the three levels of analysis and the timing of their initiatives, with an ultimate focus on exposing and changing traditional interactional departmental dynamics that serve to hinder the progress of their women faculty.

\section{Suggestions for Other Universities}

Not all departments have the resources to support a dedicated effort such as ADVANCE at their institutions. However, there are certain actions that may give significant results with fewer resources. Many of the ADVANCE initiatives require more organizing than they do funding. The key is to create a means for communication among women on campus by bootstrapping with resources already present to slowly introduce best practices that move the institution forward toward a better environment for women and others. The following are suggested: 
- $\quad$ Topical lunches - This takes very little budget and not an excessive amount of time to organize. Quick brainstorming of available dates, venue, and facilitators can be done online among a group. Participants can pay for their own meals. At URI, our Women in the Sciences group organized in this fashion for over 18 years with good result. This group has recently secured funds from the provost to pay for the lunches of the students that attend. Faculty members are usually delighted to lead a discussion about a topic for which they are recognized as an expert. The key is to keep the presentations short, inviting and informal, and to encourage discussion. One or two volunteer facilitators are required. These do not have to be STEM faculty. In the past at URI, for example, a psychologist interested in special issues for underrepresented groups and the director of the instructional development department volunteered to organize and announce the luncheons.

- $\quad$ Faculty workshops. Career workshops geared to junior faculty can be organized and facilitated by senior faculty. Many faculty are willing to share their expertise on topics such as negotiation, mentoring, lab management, etc., and consider it a service contribution. Chairs should be encouraged to recognize and reward this participation as a formal service contribution.

- Department climate change - Instead of beginning with the training of the departments most in need of change, perhaps an institution could begin with a list of "best practices" (borrowed from the ADVANCE institutions) and disseminate them to the departments via the deans. Examples can include mentoring and recruitment practices. Then they could devise a program to reward the departments that have embraced these practices. Some administrators might be convinced with information about the outcomes of best practices to assist with this. Recognitions could be announced at the topical luncheons and department chair meetings.

- Work-Life Balance Initiatives - many universities today are recognizing the need to incorporate flexible work options and provide opportunities for faculty to more effectively balance work and life. Generous parental leave policies, part-time arrangements, dual career hiring accommodations are some examples of initiatives that have long-term economic benefits to the institution. A common difficulty is a lack of awareness and visibility of whatever policies are already in place ("what parental leave policy??"). Widely publicizing to faculty and chairs (through pamphlets, presentations, etc.) what options are available will not only be enlightening for many, but will normalize these topics, and promote an environment where available options can be used by faculty without negative repercussion.

- Tactical social events for women who are isolated in science departments might be attractive to those wishing to develop social and outreach connections. For example at URI, we created two informal potluck book clubs. We have also secured complimentary tickets to our local Women's Network. This is a group of women off campus who meet on a monthly basis to make connections and highlight special efforts of local women in the county. This has included a presentation of ADVANCE activities at URI. 
a The University's administration and the AAUP mutually agreed to hire Workplace Solutions, Ithaca, New York to conduct the audit. The cost of the independent audit was borne equally by the University of Rhode Island and the AAUP

b Report of the Audit Team to the University of Rhode Island College of Engineering

\section{Bibliography}

1. American Society for Engineering Education, "The Year in Numbers," 2004 Edition of the Profiles of Engineering and Engineering Technology Colleges. Prepared by M. Gibbons, 2004. http://asee.org/about/publications/profiles/upload/2004ProfileIntro2.pdf

2. M. Lord, M, “Making It Through the Maze," ASEE Prism, vol 15, no. 2.

3. National Science Foundation, Division of Science Resources Statistics, Gender Differences in the Careers of Academic Scientists and Engineers, NSF 04-323, Project Officer, Alan I. Rapoport (Arlington, VA, 2004).

4. V. Valian, Why So Slow: The Advancement of Women. Cambridge, MA, USA: M.I.T. Press, 1998.

5. “Balancing Faculty Careers and Family Work.” Academe,. Vol 90, no. 6, November-December 2004

6. B. Risman, Gender Vertigo: American Families in Transition. New Haven, CT, USA: Yale University Press, 1998 .

7. B. Risman, "Gender as a Social Structure: Theory Wrestling with Activism," Gender \& Society, vol. 18, no. 4, pp 429-450, 2004.

8. W. Bielby, "Minimizing Workplace Gender and Racial Bias," Contemporary Sociology, vol. 29, no. 1, pp 120$129,2000$.

9. B. Reskin, "The Proximate Causes of Employment Discrimination," Contemporary Sociology, vol. 29, no. 2, pp 319-328, 2000. 